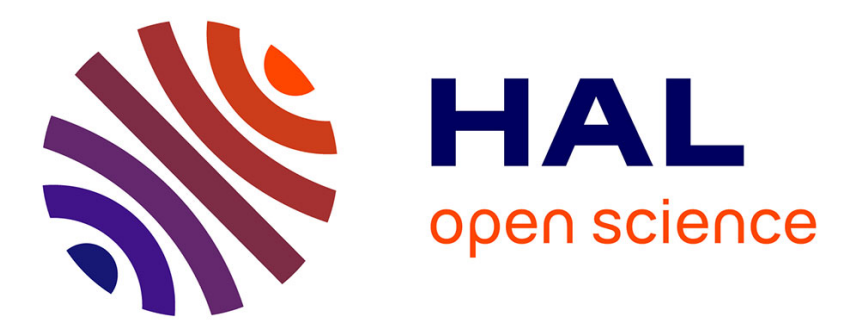

\title{
Association of with hypersensitivity induced by Taxane therapy in breast cancer patients
}

Roberta Rizzo, Federica Spaggiari, Monica Indelli, Giorgio Lelli, Olavio R. Baricordi, Paola Rimessi, Alessandra Ferlini

\section{- To cite this version:}

Roberta Rizzo, Federica Spaggiari, Monica Indelli, Giorgio Lelli, Olavio R. Baricordi, et al.. Association of with hypersensitivity induced by Taxane therapy in breast cancer patients. Breast Cancer Research and Treatment, 2010, 124 (2), pp.593-598. 10.1007/s10549-010-1034-5 . hal-00556045

\section{HAL Id: hal-00556045 https://hal.science/hal-00556045}

Submitted on 15 Jan 2011

HAL is a multi-disciplinary open access archive for the deposit and dissemination of scientific research documents, whether they are published or not. The documents may come from teaching and research institutions in France or abroad, or from public or private research centers.
L'archive ouverte pluridisciplinaire HAL, est destinée au dépôt et à la diffusion de documents scientifiques de niveau recherche, publiés ou non, émanant des établissements d'enseignement et de recherche français ou étrangers, des laboratoires publics ou privés. 


\section{Association of CYP1B1 with hypersensitivity induced by Taxane therapy in breast cancer patients.}

Roberta Rizzo*, Federica Spaggiari*, Monica Indelli, Giorgio Lelli, Olavio R Baricordi, Paola Rimessi, Alessandra Ferlini.

R. Rizzo, Olavio R. Baricordi , P. Rimessi, A. Ferlini: Department of Experimental and Diagnostic Medicine - Section of Medical Genetics - Via Fossaro di Mortasa, 74 - University of Ferrara - 44121- Ferrara - Italy

F. Spaggiari, M. Indelli, G.Lelli: Oncology Unit - Azienda Ospedaliera-Universitaria Arcispedale S.Anna - Corso Giovecca 203 - 44121 Ferrara-Italy

* Contributed equally to the study

Corresponding author: Alessandra Ferlini

University of Ferrara - Department of Experimental and Diagnostic Medicine - Section of Medical Genetics

Via Fossato di Mortara, 74 - 44121 Ferrara (Italy)

Tel:+390532974439

Fax: +390532974406

E-mail: fla@unife.it 


\begin{abstract}
Purpose: Taxanes represent a group of anticancer drugs with a wide range of activity against breast cancer. Therapy side effects include haematologic toxicity (neutropenia, leucopenia), peripheral neuropathy and hypersensitivity, and demonstrate inter-individual variations. Since it is known that three genes are implicated in Taxane turnover, namely $A B C B 1$ in the transport, $C Y P 2 C 8$ in the metabolism and $C Y P 1 B 1$ in the activity, we explored the association among polymorphisms (SNPs) in these three genes and the occurrence of Taxane-induced toxicity.

Methods: We studied 95 patients affected by breast cancer and under treatment with Taxanes as adjuvant, metastatic or neoadjuvant therapy. We genotyped them for single nucleotide polymorphisms in the CYP2C8 (alleles *1, *2*3 and *4), CYP1B1 (alleles *1 and *3) and ABCB1 (1236 C>T; $2677 \mathrm{G}>\mathrm{T} / \mathrm{A} ; 3435 \mathrm{C}>\mathrm{T})$ genes by Real-Time PCR assay.

Results: We observed a significant association between the $C Y P 1 B 1 * 3$ allele and a lower occurrence of hypersensitivity reactions to Taxane treatment.

Conclusions: We speculate that the highest production of 4-hydroxyestradiol (4-OHE2) metabolite by CYP1B1*3 allele could increase the formation of the 4-OHE2-Taxane adduct and possibly inhibit Taxane toxicity. We suggest that $C Y P 1 B 1$ might affect Taxane hypersensitivity therefore representing, if confirmed in a large cohort of patients, an exploratory hypersensitivity predictive biomarker .
\end{abstract}

Keywords: Taxane; breast cancer; $A B C B 1$; $C Y P 2 C 8$; $C Y P 1 B 1$; biomarkers. 


\begin{tabular}{ll} 
Abbreviations & \\
\hline SNPs & Single nucleotide polymorphisms \\
CYP & Cytochrome P450 superfamily \\
ABCB1 & ATP-binding cassette, sub-family B (MDR/TAP), member 1 \\
4-OHE2 & 4-hydroxyestradiol \\
NCI & National Cancer Institute \\
rs & Reference cluster ID \\
VAR1 & Homozygous variant 1 \\
HT & Heterozygous \\
VAR2 & Homozygous variant 2 \\
NA & Not applicable \\
\hline
\end{tabular}




\section{Introduction}

Inter-individual differences in drug efficacy and toxicity, resulting in unpredictable therapy responses, are commonly observed in all therapeutic areas, mainly in cancer therapy. In many cases such variability is linked to polymorphisms (or single nucleotide polymorphisms, SNPs) in genes coding for drug-metabolizing enzymes. Nowadays, among anticancer drugs, Taxanes are of particular interest because of their wide range of activity against breast cancer. Taxanes stabilize microtubules at the mitotic spindle resulting in cell cycle arrest during mitosis and apoptosis [1]. Therapy-limiting side effects include haematologic toxicity (neutropenia, leucopenia), peripheral neuropathy and hypersensitivity [2], which vary considerably among patients. Even though several studies have focused on transporter and drug-metabolism genes, very little progress has been made in the identification of pharmacogenetic markers for Taxane toxicity [3, 4]. Cellular toxicity induced by Taxanes is likely to be controlled by the action of multiple gene products [4]: (i) the cytochrome P450 CYP2C8 which hydroxylates Taxanes as one of the primary routes of elimination [5, 6]; (ii) $A B C B 1$ (ATP-binding cassette, subfamily B (MDR/TAP), member 1) gene product P-glycoprotein which enables the elimination through hepatobiliary and intestinal secretion of the parent drug [7]; (iii) cytochrome P450 CYP1B1, a tumour-related form of cytochrome P450 which is over expressed in breast cancer and in a wide variety of primary tumours of different histological types [8, 9]. It has been suggested that variability in expression and/or function of these proteins, caused by SNPs, may account for the interindividual differences in drug response and toxicity. The CYP2C $8 * 2$ and $* 3$ variant alleles have been associated with in vitro decreased metabolism of Paclitaxel [10]. On the contrary, clinical data failed to associate $C Y P 2 C 8 * 3$ allele with Paclitaxel pharmacokinetics [11]. ABCB1 gene polymorphisms have been correlated with Paclitaxel pharmacokinetics, clearance, response and toxicity, even though with inconsistent results [12-16]. However, no systematic data are available on the role of these three genes variations in predicting the Taxane-induced toxicity.

In the present study, we retrospectively evaluated whether known variant alleles of CYP2C8 (416 G>A; $792 \mathrm{C}>\mathrm{G} ; 805$ $\mathrm{A}>\mathrm{T} ; 1196 \mathrm{~A}>\mathrm{G}), A B C B 1(1236 \mathrm{C}>\mathrm{T} ; 2677 \mathrm{G}>\mathrm{T} / \mathrm{A} ; 3435 \mathrm{C}>\mathrm{T})$ and $C Y P 1 B 1(4326 \mathrm{C}>\mathrm{G})$ genes are associated with the Taxane-induced toxicity in adult Caucasian breast cancer patients. The polymorphisms assessed in this study were selected on the basis of previously described associations $[17,18]$ We enrolled 95 patients affected by breast cancer and under treatment with Taxanes as adjuvant, metastatic or neo-adjuvant therapy. We observed a significant association between the $C Y P 1 B 1 * 3$ allele and a lower occurrence of hypersensitivity reactions to Taxane treatment. We speculate that the highest production of 4-hydroxyestradiol (4-OHE2) estrogen metabolite by $C Y P 1 B 1 * 3$ allele could increase the formation of the 4- 
OHE2-Taxane adduct [19], reducing Taxane toxicity. This could explain the implication of the $C Y P 1 B 1 * 3$ allele in protecting from the hypersensitivity reaction.

We therefore suggest that the CYPIBI $4326 \mathrm{C} / \mathrm{G}$ genotype may influence Taxane-induced hypersensitivity and may represent, if confirmed in a large patients cohort, an exploratory hypersensitivity predictive biomarker. 


\section{Materials and Methods}

1. Patient selection.

Our retrospective analysis was based on 95 eligible patients with histologically confirmed diagnosis of breast cancer treated with Taxane-based chemotherapy at the Oncology Unit of St. Anna Hospital of Ferrara. From October 2008 to December 2009 we recruited patients who had received Docetaxel or Paclitaxel either as adjuvant, locally advanced or metastatic treatment.

The study protocol was approved by the local ethical review boards, and all patients provided written informed consent before study entry. The patient baseline characteristics are reported in Table 1.

\section{Drug administration.}

Paclitaxel (Anzatax ${ }^{\circledR}$ ) was administered at the standard dose of $80 \mathrm{mg} / \mathrm{m}^{2}$ infused i.v. over $1 \mathrm{~h}$ weekly and Docetaxel (Taxotere®-Sanofi Aventis) was administered at the dose of 75 or $100 \mathrm{mg} / \mathrm{m}^{2}$ infused i.v. over $1 \mathrm{~h}$ every three weeks. All patients received a standard premedication with corticosteroids. All patients but two underwent a previous or combined treatment with other cytotoxic drugs including anthracyclines.

\section{Toxicity evaluation.}

This study focused on Taxane-dependent haematologic, neurologic and hypersensitivity adverse events. These toxicities were graded according to National Cancer Institute (NCI) Common Toxicity Criteria, version 3.0 [20]. In our series of 95 patients we observed paclitaxel-associated hypersensitivity reactions in three of twenty-five patients treated with this agent $(12 \%)$ and docetaxel-associated hypersensitivity reactions in twenty of seventy patients who underwent this therapy (28\%). The hypersensitivity reactions were characterized by acute dyspnea, flushing of the face, chest constraint, hypotension and rash.

Nine patients developed an acute hypersensitivity reaction at the beginning of the first infusion of Taxane-based chemotherapy; therefore these cases were not evaluated for haematologic and neurologic toxicity. We observed grade 3 neutropenia in seven cases treated with Paclitaxel and in five cases treated with Docetaxel, and grade 4 neutropenia in two cases treated with Paclitaxel and in seventeen cases treated with Docetaxel. As regards neurotoxicity, we observed a grade 1 sensory neuropathy in one patient who received Paclitaxel and six cases of grade 2, two treated with Docetaxel and four with Paclitaxel. The Taxane-dependent adverse events that we observed in our series are resumed in Table 2; the toxicities reported were reversible at the suspension of the treatment. 
4. Pharmacogenetic analysis.

Genomic DNA was purified from $1 \mathrm{ml}$ of peripheral blood using the BioRobot Universal System (Qiagen, Düsseldorf, DE) following the manufacturer's instructions. SNPs in CYP2C8, CYP1B1 and ABCB1 (Table 2) were analyzed using precustom Real-Time PCR assays (Applied-Biosystems, CA, USA) (Table 3), following the manufacturer's instructions. Briefly, 50 ng of genomic DNA were amplified on Real Time 7900HT apparatus (Appled-Biosystems CA, USA) in a final reaction volume of $25 \mu 1$ with $12.5 \mu 1$ of TaqMan Universal PCR Master Mix and $1.25 \mu 1$ of TaqMan Drug Metabolism Genotyping Assay Mix (Table 3). The amplification was performed with one hold at $50^{\circ} \mathrm{C}$ for 2 minutes, one hold at $95^{\circ} \mathrm{C}$ for 10 minutes and 50 cycles at $92^{\circ} \mathrm{C}$ for 15 seconds and $60^{\circ} \mathrm{C}$ for 90 seconds. The analysis was performed with an endpoint plate read using an Applied Biosystem Sequence Detection System.

\section{Statistical evaluation}

Hardy-Weinberg equilibrium was assessed on genotype-frequencies. The significance of differences in allele frequencies and genotypes between patients with or without toxicity events was calculated using generalized Pearsons's $\mathrm{X}^{2}$ test (the P values for the two-sided exact significance are presented) and the Bonferroni's correction for multiple comparisons (pc). Confirmation of significant associations was performed by logistic regression analysis (STATView software). The values of $\mathrm{P}<0.05$ were considered as significant. 


\section{Results}

Genomic DNA from 95 adult Caucasian patients with breast cancer diagnosis and with a mean age of $57+/-10$ years (Table 1) was genotyped. Eight SNPs in three genes of known relevance for Taxane turnover were analyzed (Table 3). The allele frequencies for $C Y P 2 C 8 * 2, C Y P 2 C 8 * 3, C Y P 2 C * 4, C Y P 1 B 1 * 3$ and $A B C B 13435 C>T, 2677 G>T / A, 1236 C>T$ genotypes are reported in Table 4. All genotype frequencies were found to be in Hardy-Weinberg equilibrium (Table 4).

For one SNP in the CYP2C8 gene $(C Y P 2 C 8 * 2,805 A>T)$, no variant allele was observed, as expected based on previously published data obtained from Caucasian individuals [10].

Using $\mathrm{X}^{2}$ analysis, no significant association was found with $A B C B 1$ and $C Y P 2 C 8$ alleles and toxicity reactions (Table 5). On the contrary, the presence of the $C Y 1 B 1 * 3$ allele in heterozygosity (Table 5: $\mathrm{p}_{\mathrm{c}}$ : 0.00008) (OR: 0.1361; CI 95\%: 0.0494$0.3752)$ or in homozygosity $(\mathrm{p}=0.0024 ; \mathrm{p}=0.0144)$ decreases the risk of hypersensitivity. The logistic regression analysis confirmed the significant association between the presence of the $C Y P 1 B 1 * 3$ allele and decreased hypersensitivity without any implication of all the other variables (Table 6). 


\section{Conclusions}

In this pilot study, we investigated whether the toxicity induced by Taxane treatment could depend on the genetic variability of $C Y P 2 C 8, C Y P 1 B 1$ and $A B C B 1$ genes.

Our results confirm the absence of an association among $C Y P 2 C 8$ and $A B C B 1$, and Taxane-dependent toxicity [21]. We did not find any association among the eight SNPs studied and haematologic and neurologic toxicity but, intriguingly, we observed a significant association between $C Y P 1 B 1 * 1$ allele and hypersensitivity reactions. CYP1B1 is an enzyme which catalyzes the extrahepatic 4-hydroxylation of $17 \mathrm{~h}$-estradiol into the less active metabolite, 4-OHE2 (4-hydroxyestradiol) that has a potential carcinogenic effect [22]. CYP1B1 expression is particularly high in hormone-mediated cancers such as breast cancer [23] and it has been suggested a possible implication in the carcinogenic process [24]. We identified a 7 times increased risk of hypersensitivity reactions ( $\mathrm{OR}=7.35$; CI 95\%: 2.6664-20.2604) in patients homozygous for the CYP1BI*1 allele; on the contrary the $C Y P 1 B 1 * 3$ allele in heterozygosity or in homozygosity decreases the risk of hypersensitivity. These data are in agreement with the suggested role of CYP1B1 $4326 \mathrm{C}>\mathrm{G}$ polymorphism in Taxane toxicity. Taxanes are not metabolized by CYP1B1 but they bind the enzyme [25]. The CYP1B1*3 allele is associated with increased CYP1B1 mRNA expression [26], catalytic activity [27 - 29], higher affinity for Taxanes reducing the availability of active drug and possibly its toxicity. Our results sustain these data, reporting the implication of CYPIBI in the Taxane-induced hypersensitivity. We can speculate that the increased production of 4-OHE2 metabolite due to CYP1BI*3 allele could create an adduct which inhibits the Taxane toxicity [19]. CYP1B1 seems to encode an enzyme with a role in controlling hypersensitivity.

The possibility to identify the subjects with an increased risk of hypersensitivity could help in the clinical effort to deliver a personalized medicine. Moreover our results are important in understanding the molecular mechanisms and the physiopathological bases causing Taxane-associated hypersensitivity reactions with implications in the development of Taxane formulations that minimize the risk or optimize the premedication regimen, not only for breast cancer but possibly for all the solid tumors treated with Taxanes.

Our pilot study demonstrates a proof of principle of CYP1B1 haplotype role to be further exploited in a larger patients' cohort. However, supporting our hypothesis is the very highly significant $\mathrm{p}$ value we have found related to the small populations studied, as well as the pathophysiological hypothesis. 
In conclusion our results suggest that the $C Y P 1 B 1(4326 C>G)$ could be used as exploratory biomarker predicting the risk of Taxane-induced hypersentivity reactions and is valuable to be further confirmed and possibly proposed as pharmacogenetic biomarker facilitating personalized treatment for Taxanes therapy with reduced adverse effects.

Acknowledgments This work was supported by the "Programma Ricerca Regione Università 2007/2009" Area 1A: Innovative Research.: The Contribution of Novel Technologies to the improvement of Diagnosis/Therapies in Breast Cancer by Explorating Susceptibilty Genes/Factors. (to A.F.) .

Conflict of interest statement: The authors declare no conflict of interest. 


\section{References}

1. Abal M, Andreu JM, Barasoain I. (2003) Taxanes: microtubule and centrosome targets, and cell cycle dependent mechanisms of action. Curr Cancer Drug Targets. 3: 193-203.

2. Markman M. (2003) Management of toxicities associated with the administration of taxanes. Expert Opin Drug Saf 2: 141-146.

3. Steed H, Sawyer M.B. (2007) Pharmacology, pharmacokinetics and pharmacogenomics of paclitaxel. Pharmacogenomics 8: 803-815.

4. Marsh S. (2006) Taxane pharmacogenetics. Personalized Med 3: 33-43.

5. Harris JW, Rahman A, Kim BR, Guengerich FP, Collins JM. (1994) Metabolism of taxol by human hepatic microsomes and liver slices: participation of cytochrome P450 3A4 and an unknown P450 enzyme. Cancer Res 54: 4026-4035.

6. Rahman A, Korzekwa KR, Grogan J, Gonzalez FJ, Harris JW. (1994) Selective biotransformation of taxol to 6 ahydroxytaxol by human cytochrome P450 2C8. Cancer Res 54: 5543-5546.

7. Sparreboom A, van Asperen J, Mayer U, et al. (1997) Limited oral bioavailability and active epithelial excretion of paclitaxel (Taxol) caused by P-glycoprotein in the intestine. Proc Natl Acad Sci U S A 94: 2031-2035.

8. Iscan M, Klaavuniemi T, Coban T, Kapucuoglu N, Pelkonen O, Raunio H. Breast Cancer Res. Treat. 2001. 70: 47-54.

9. McFadyen MC Cruickshank ME, Miller ID, et al. (2001) Cytochrome P450 CYP1B1 over-expression in primary and metastatic ovarian cancer. Br J Cancer 85: 242-246.

10. Bahadur N, Leathart JB, Mutch E, et al. (2002) CYP2C8 polymorphisms in Caucasians and their relationship with paclitaxel 6a-hydroxylase activity in human liver microsomes. Biochem Pharmacol 64: 1579- 1589.

11. Daily EB, Aquilante CL. (2009) Cytochrome P450 2C8 pharmacogenetics: a review of clinical studies. Pharmacogenomics 9: 1489-1510.

12. Sissung TM, Mross K, Steinberg SM, et al. (2006) Association of ABCB1 Genotypes with Paclitaxel-mediated Peripheral Neuropathy and Neutropenia. Eur J Cancer 42: 2893-2896.

13. Bosch TM, Huitema AD, Doodeman VD, Jansen R, et al. (2006) Pharmacogenetic screening of CYP3A and ABCB1 in relation to population pharmacokinetics of docetaxel. Clin Cancer Res 12: 5786-5793.

14. Green H, Soderkvist P, Rosenberg P, Horvath G, Peterson C. (2006) MDR-1single nucleotide polymorphisms in ovarian cancer tissue: G2677T/A correlateswith response to paclitaxel chemotherapy. Clin Cancer Res 12: 854-859.

15. Marsh S, King CR, McLeod HL, Paul J, Gifford G, Brown R (2006) ABCB1 2677G>T/A genotype and paclitaxel pharmacogenetics in ovarian cancer. Clin Cancer Res. 12: 4127-4129. 
16. Marzolini C, Paus E, BuclinT, KimRB. (2004) Polymorphisms in humanMDR1 (P-glycoprotein):recent advances and clinical relevance. Clin Pharmacol Ther 75: 13- 33.

17. Marsh S, Somlo G, Li X, et al. (2007) Pharmacogenetic analysis of paclitaxel transport and metabolism genes in breast cancer. Pharmacogenomics J 7: 362-365.

18. Marsh S, McLeod HL. (2007) Pharmacogenetics and oncology treatment for breast cancer. Expert Opin Pharmacother 8: $119-127$.

19. Sissung TM, Danesi R, Price DK, et al. (2008) Association of the CYP1B1*3 allele with survival in patients with prostate cancer receiving docetaxel. Mol Cancer Ther 7: 19-26.

20. Common Terminology Criteria for Adverse Events v3.0 (publish date; August 9, 2006). Available at http://ctep.cancer.gov/protocolDevelopment/electronic_applications/docs/ctcaev3.pdf

21. Marsh S, Paul J, King CR, Gifford G, McLeod HL, Brown R. (2007) Pharmacogenetic assessment of toxicity and outcome after platinum plus taxane chemotherapy in ovarian cancer: the Scottish Randomised Trial in Ovarian Cancer. J Clin Oncol 25: 4528-4535.

22. Liehr JG, Rocci MJ. (1996) 4-Hydroxylation of estrogens as marker of human mammary tumors. Proc. Natl Acad. Sci. USA, 93: 3294-3296.

23. McFayden MCE, McLeod HL, Jackson FC, Mel Vin WT, Doehmer J, Murray GI. (2001) Cytochrome P450 CYP1B1 protein expression: a novel mechanism of anticancer drug resistance. Biochem Pharmacol 62: 207-212.

24. Li DN, Seidel A, Pritchard MP, Wolf CR, Friedberg T. (2000) Polymorphisms in P450 CYP1B1 affect the conversion of estradiol to the potentially carcinogenic metabolite 4-hydroxyestradiol. Pharmacogenetics 10: 343 - 353 .

25. Bournique B, Lemarie A. (2002) Docetaxel (Taxotere) is not metabolized by recombinant human CYP1B1 in vitro, but acts as an effector of this isozyme. Drug Metab Dispos 30: 1149-1152.

26. Landi MT, Bergen AW, Baccarelli A, et al. (2005) CYP1A1 and CYP1B1 genotypes, haplotypes, and TCDD-induced gene expression in subjects from Seveso, Italy. Toxicology 207: 191-202.

27. Shimada T, Watanabe J, Kawajiri K, et al. (1999) Catalytic properties of polymorphic human cytochrome P450 $1 \mathrm{~B} 1$ variants. Carcinogenesis 20: 1607-1613.

28. Hanna IH, Dawling S, Roodi N, Guengerich FP, Parl FF. (2000) Cytochrome P450 1B1 (CYP1B1) pharmacogenetics: association of polymorphisms with functional differences in estrogen hydroxylation activity. Cancer Res 60: 3440-3444.

29. Li DN, Seidel A, Pritchard MP, Wolf CR, Friedberg T. (2000) Polymorphisms in P450 CYP1B1 affect the conversion of estradiol to the potentially carcinogenic metabolite 4-hydroxyestradiol. Pharmacogenetics 10: 343-353. 
Table 1. Baseline patients characteristics.

\begin{tabular}{lc}
\hline \multicolumn{1}{c}{ Characteristics } & Patients (95) \\
$\mathbf{N}(\boldsymbol{\%})$
\end{tabular}


Table 2. The Taxane-dependent toxicities ${ }^{\mathrm{a}}$

\begin{tabular}{cc}
\hline $\begin{array}{l}\text { Haematologic toxicity (NCI) } \\
\text { Neutropenia grade }\end{array}$ & $\begin{array}{c}\text { Patients (95) } \\
\mathbf{N}(\boldsymbol{\%})\end{array}$ \\
\hline $\mathbf{3}$ & $12(14 \%)$ \\
$\mathbf{4}$ & $19(22 \%)$ \\
\hline Neurotoxicity (NCI) & \\
Sensory neuropathy grade & $1(1 \%)$ \\
\hline $\mathbf{1}$ & $6(7 \%)$ \\
$\mathbf{2}$ & 0 \\
$\mathbf{3}$ & 0 \\
\hline Hypersensitivity reaction & \\
\hline Present & $23(24 \%)$ \\
Absent & $72(76 \%)$
\end{tabular}

${ }^{a}$ Toxicity was evaluated accordingly to National Cancer Institute (NCI) Common Toxicity Criteria, version 3.0 [20]. 
Table 3. Real-Time PCR assays

\begin{tabular}{|c|c|c|c|c|}
\hline$\overline{\text { Polymorphism }^{a}}$ & Nomenclature & Effect $^{b}$ & $\mathrm{rs}^{\mathrm{c}}$ & Real-Time PCR assay $^{\mathrm{d}}$ \\
\hline $\mathrm{ABCB} 11236 \mathrm{C}>\mathrm{T}$ & NA & G412G & 11285503 & C_7586662 \\
\hline ABCB1 $2677 \mathrm{G}>\mathrm{T}$ & NA & A893S & 2032582 & C_11711720D \\
\hline ABCB1 $2677 \mathrm{G}>\mathrm{A}$ & NA & A893S & 2032582 & C_11711720C \\
\hline $\mathrm{ABCB} 13435 \mathrm{C}>\mathrm{T}$ & NA & I1145I & 1045642 & C_7586657 \\
\hline CYP2C8 416 G>A & CYP2C $8 * 3$ & $\mathrm{R} 139 \mathrm{~K}$ & 11572080 & C_25625794 \\
\hline CYP2C8 $792 \mathrm{C}>\mathrm{G}$ & CYP2C $8 * 4$ & $\mathrm{I} 264 \mathrm{M}$ & 1058930 & C_25761568 \\
\hline CYP2C8 $805 \mathrm{~A}>\mathrm{T}$ & CYP2C $8 * 2$ & I269F & 11572103 & C_30634034 \\
\hline CYP2C8 1196 A>G & CYP2C $8 * 3$ & K399R & 10509681 & C_25625782 \\
\hline CYP1B1 4326 C>G & CYP1B $1 * 3$ & L432V & 1056836 & C_3099976 \\
\hline
\end{tabular}

Abbreviations: NA, not applicable.

${ }^{a}$ Number represents position in nucleotide sequence.

${ }^{\mathrm{b}}$ Number represents amino acid codon.

${ }^{c}$ Reference cluster ID.

${ }^{\mathrm{d}}$ Applied-Biosystems pre-custom Real-Time PCR. 
Table 4. Genotype and allele frequencies for the studied variant genes.

\begin{tabular}{|c|c|c|c|c|c|c|c|}
\hline \multirow{2}{*}{$\begin{array}{c}\text { Polymorphism }^{\mathrm{a}} \\
\text { VAR1>VAR2 }\end{array}$} & \multirow[t]{2}{*}{ Nomenclature } & \multirow[t]{2}{*}{ Effect $^{b}$} & \multicolumn{3}{|c|}{ Genotype frequencies $^{c}$} & \multicolumn{2}{|c|}{ Allele frequencies $^{d}$} \\
\hline & & & VAR1 & HT & VAR2 & $\mathbf{p}$ & $\mathbf{q}$ \\
\hline ABCB1 $1236 \mathrm{C}>\mathrm{T}$ & NA & G412G & $32(34)$ & $39(41)$ & $24(25)$ & 0.54 & 0.45 \\
\hline ABCB1 2677 G>T/A & NA & A893S & $26(27)$ & $43(46)$ & $26(27)$ & 0.5 & 0.5 \\
\hline $\mathrm{ABCB} 13435 \mathrm{C}>\mathrm{T}$ & NA & I1145I & $23(24)$ & $41(43)$ & $31(33)$ & 0.46 & 0.54 \\
\hline CYP2C8 416 G>A & CYP2C $8 * 3$ & R139K & 73 (77) & $22(23)$ & $0(0)$ & 0.88 & 0.12 \\
\hline CYP2C8 792 C>G & CYP2C $8 * 4$ & $\mathrm{I} 264 \mathrm{M}$ & $83(87)$ & $12(13)$ & $0(0)$ & 0.94 & 0.06 \\
\hline CYP2C8 805 A>T & CYP2C $8 * 2$ & $\mathrm{I} 269 \mathrm{~F}$ & $95(100)$ & $0(0)$ & $0(0)$ & 1 & 0 \\
\hline CYP2C8 1196 A>G & CYP2C $8 * 3$ & K399R & $58(61)$ & $30(30)$ & $7(7)$ & 0.77 & 0.23 \\
\hline CYP1B1 4326 C>G & CYP1B1 *3 & L432V & $34(36)$ & $41(43)$ & $20(21)$ & 0.57 & 0.43 \\
\hline
\end{tabular}

Abbreviations: VAR1, homozygous variant 1; HT, heterozygous ; VAR2, homozygous variant 2; NA, not applicable. ${ }^{a}$ Number represents position in nucleotide sequence.

${ }^{\mathrm{b}}$ Number represents amino acid codon.

${ }^{\mathrm{c}}$ Number represents number of patients with percentage in parenthesis.

${ }^{\mathrm{d}}$ Hardy-Weinberg notation for allele frequencies (p, frequency for wild-type allele; $q$, frequency for variant allele). 
Table 5. Uncorrected $\mathrm{p}$ values from $\mathrm{X}^{2}$ analysis.

\begin{tabular}{llllll}
\hline Polymorphism $^{\text {a }}$ & Nomenclature & Effect $^{\text {b }}$ & Haematologic & Neurotoxicity & Hypersensitivity \\
\hline ABCB1 1236 C>T & NA & G412G & 0.8838 & 0.0618 & 0.8693 \\
ABCB1 2677 G>T/A & NA & A893S & 0.6961 & 0.1286 & 0.0735 \\
ABCB1 3435 C>T & NA & I1145I & 0.7047 & 0.6034 & 0.4147 \\
CYP2C8 416 G>A & CYP2C8 *3 & R139K & 0.3677 & 0.6664 & 0.4632 \\
CYP2C8 792 C>G & CYP2C8 *4 & I264M & 0.5526 & 0.9788 & 0.0914 \\
CYP2C8 805 A > T & CYP2C8 *2 & I269F & NA & NA & NA \\
CYP2C8 1196 A >G & CYP2C8 *3 & K399R & 0.6898 & 0.4283 & 0.7447 \\
CYP1B1 4326 C>G & CYP1B1 *3 & L432V & 0.5369 & 0.2328 & $<0.00001 * *$ \\
\hline
\end{tabular}

Abbreviations: NA, not applicable.

${ }^{a}$ Number represents position in nucleotide sequence.

${ }^{b}$ Number represents amino acid codon.

**This association passes the treshold for selection after correction for multiple testing. 
Table 6. Logistic regression for hypersensitivity.

\begin{tabular}{lc}
\hline Indipendent Variables & $\mathbf{p}$ \\
Age & 0.1141 \\
Hystotype & 0.8410 \\
Metastatic/adiuvant & 0.5422 \\
ABCB1 1236 C>T & 0.3977 \\
ABCB1 2677 G>T/A & 0.1704 \\
ABCB1 3435 C>T & 0.9926 \\
CYP2C8 416 G>A & 0.8204 \\
CYP2C8 792 C>G & 0.1122 \\
CYP2C8 805 A > T & NA \\
CYP2C8 1196 A>G & 0.6858 \\
CYP1B1 4326 C>G & $0.0015 * *$ \\
\hline
\end{tabular}

Abbreviations: NA, not applicable.

**This association passes the threshold for selection after correction for multiple testing. 